\title{
A ÁFRICA TEM UMA HISTÓRIA
}

UNESCO, Comitê Científico Internacional da UNESCO para Redação da História Geral da África. História geral da África. Tradução e revisão coordenadas por Valter Silvério. Brasilia: UNESCO, 2010. 8 vols. Disponível em http://portal.mec.gov.br/index.php? option=com_ content $\&$ view $=$ article $\& i d=16146$

"A África tem uma História". Com
essa frase, o grande historiador
Joseph Ki-Zerbo, nascido em Burkina
Fasso, abriu sua introdução à coleção História Geral da África, editada pela UNESCO a partir de trabalhos discutidos em seminários na década de 1960, e escritos ao longo das décadas de 1970 e 1980 . São oito volumes, publicados em inglês, francês e árabe, em torno de dez mil páginas escritas por cerca de trezentos e cinquenta estudiosos, coordenados por trinta e nove consultores. Dessa obra grandiosa, apenas quatro volumes haviam sido traduzidos ao português e editados em versão impressa no Brasil. No ano de 2010, o governo brasileiro, em parceria com a UNESCO, tornou disponível na internet, e com acesso livre para leitura e reprodução, os oito volumes traduzidos em língua portuguesa.

A coleção foi elaborada logo após o período das independências de muitos países africanos, depois de décadas de domínio europeu sobre amplas áreas dos seus territórios. A frase de Ki-Zerbo se colocava, afirmativamente, frente a uma história de negação que deixara fortes rastros de ignorância e incompreensão sobre a experiência africana. A visão sobre a história da África que esse projeto das Nações Unidas pretendia combater em grande parte fora construída no período colonial, iniciado em fins do século XIX e que chegou até o último quartel do século XX, com a libertação das colônias portuguesas em meados da década de 1970. Mas, esse pensamento também se alimentara da longa história do tráfico transatlântico de escravos, quando foram criadas justificativas para o "infame comércio". Era uma visão que negava à África o direito à sua história e aos africanos o papel de sujeitos e não apenas objeto de dominação, conversão ou escravização. A contribuição dos estudiosos do próprio continente, com agendas próprias e sólidos trabalhos de pesquisa, trouxe novas luzes para este campo do saber. Seus 
trabalhos, ao mesmo, tempo enriqueceram a análise geral com os dados de processos históricos locais, e inseriram os africanos de forma ativa na construção de uma história que ia além das fronteiras de seu continente.

A coleção História Geral da África pretendeu se pautar nos quatro grandes princípios que J. Ki-Zerbo destacou na introdução ao primeiro volume, os quais, apesar do tempo decorrido, ainda são de grande atualidade. O primeiro de todos, e que pretendia ser uma postura sistemática para o estudo da história do continente africano: a interdisciplinaridade. Para entender as conjunturas, os processos mais duradouros e a maneira como as informações foram produzidas e chegaram ao alcance dos pesquisadores e estudiosos, seria, como ainda é, fundamental o auxílio de outras disciplinas, como geografia, sociologia, antropologia, linguística, entre outras.

Outro importante ponto de partida era buscar sempre apresentar a história desde o ponto de vista africano, e não de fora para dentro. Isso não queria dizer ignorar os processos compartilhados e as conexões, mas sim perceber a reciprocidade das influências, as ações que partiram dos africanos na construção de sua história. $\mathrm{O}$ terceiro princípio seria o de apresentar a história dos povos africanos em seu conjunto, não numa perspectiva simplista que não perce- besse a pluralidade e a diversidade na África, mas entendendo as conexões e trocas, bem como as semelhanças entre muitas sociedades do continente - e aqui entrava o método comparativo. Finalmente, o quarto princípio seria o de evitar o meramente factual, ou seja, uma história de eventos dissociados, que tanto mal fez e faz à aprendizagem crítica, ao entendimento das relações entre as diversas partes do mundo e à compreensão dos sujeitos históricos em toda sua complexidade.

Uma obra dessa magnitude, trazendo em cada um de seus oito volumes mais de trinta colaboradores, cobrindo, em suas áreas de especialidades, períodos longos de tempo ou conjunturas com muitas mudanças, desde o começo estava marcada por problemas advindos de sua própria grandiosidade. Uma síntese ousada do projeto - mais ainda porque pensada a partir de um campo de luta política - poderia ser: descolonizar a história da África. Tal aspecto fez com que, sobre sua produção, se olhasse com esperança e ao mesmo tempo com desconfiança, dependendo de onde partia esse olhar. A atuação dos membros do comitê científico organizador da obra gerou uma discussão prolongada ao longo de todo o processo de escolha de nomes, elaboração e publicação dos volumes. Havia crítica de todos os lados, fosse a cobrança por um posicionamento 
combativo mais explícito, fosse para que os autores assumissem um distanciamento que garantisse o desejado estatuto científico à coleção.

Um dos pontos chaves do debate girou em torno da perspectiva interna à África que deveria nortear a obra. O historiador brasileiro Muryatan Barbosa, que atualmente pesquisa sobre o tema, chama essa opção de "a perspectiva africana como prerrogativa historiográfica". ${ }^{1}$ Essa postura fez com que dois terços dos autores fossem africanos, levando a que muitas vezes especialistas não africanos mais renomados ficassem de fora. Além disso, na abordagem de certas temáticas, alguns autores priorizaram os fatores internos ao continente, em detrimento dos externos, para a explicação de processos históricos e movimentos sociais. Como já havia declarado, em 1978, Bethwell Ogot, então presidente do Conselho Científico Internacional para a Redação da História Geral da África: "Neste projeto, a história da África é enfocada sob o ponto de vista da própria África". ${ }^{2}$

1 Muryatan S. Barbosa, "Perspectiva africana na História Geral da África”. Trabalho apresentado no Simpósio Temático De que África estamos falando: perspectivas da pesquisa histórica e do ensino de História da África, XXVI Simpósio Nacional de História da ANPUH, São Paulo, 17 a 22 de julho de 2011.

2 Citado por Barbosa, "Perspectiva Africana", p. 3
A dimensão da obra e a diversidade de temas e autores fizeram a História Geral da África ser, por vezes, classificada como um desafio do ponto de vista metodológico, pois trazia em si a controvérsia, ou resultava simplesmente contraditória, pelas diferenças de opinião e a desigualdade no tratamento das temáticas em pauta. A polêmica interna, no entanto, pareceu ser bem menor do que a surgida externamente, ao longo dos anos em que foram saindo os volumes. As revistas especializadas na Europa, Estados Unidos e Canadá publicaram resenhas na medida em que os volumes apareciam, com muitas críticas de especialistas e por vezes de não-especialistas em História da África.

A objeção mais comum que se fez foi sobre o caráter datado da coleção, iniciada na década de sessenta a partir de pontos de vista que teriam sidos mantidos durante a década de setenta, quando foi em grande parte escrita. As novas perspectivas, interpretações e mesmo achados empíricos não teriam sido incorporados por autores associados às gerações anteriores. A obra encontrar-se-ia, portanto, desatualizada na altura de sua entrega ao público, entre os anos oitenta e início dos noventa do século XX. Além disso, muitas críticas se fizeram ao fato desta ser trabalho engajado além do que seria apropriado numa obra historiográfica - caracte- 
rística que estaria presente em diversos capítulos e na coordenação de alguns volumes da obra. Segundo alguns estudiosos de História da África, autores de resenhas críticas sobre a coleção, essa postura produziria um viés por vezes marcado pelo afrocentrismo ou, o que seria ainda pior, por concepções equivocadas de defesa de uma supremacia da raça negra, a título de inversão de concepções racistas do Ocidente europeu e euro-americano. Entre os críticos mais influentes da coleção, que eventualmente ressalvaram o conteúdo de alguns dos capítulos e o valor historiográfico de alguns volumes, mas que sinalizaram desfavoravelmente seu descompasso com a pesquisa histórica e seu viés, a seu ver, excessivamente afrocêntrico e ideologizado, encontramos Joseph Miller (Universidade de Virginia), Randall L. Pouwells (Universidade de ArkansaS), Roland Oliver (Universidade de Londres) e Richard Rathbone (Universidade de Londres), entre outros.

Entre as críticas específicas aos volumes, as que se referiram ao primeiro volume, Metodologia e préhistória da África, organizado por J. $\mathrm{Ki}$-Zerbo, assinalavam como problema o descompasso entre as duas partes integrantes. A primeira parte traz textos sobre o tratamento metodológico da obra e sobre os problemas e desafios da pesquisa em história da África e, na segunda parte, os capítu- los dedicados aos estudos sobre a préhistória seriam de caráter descritivo, utilizando por vezes um vocabulário excessivamente técnico do campo da arqueologia. Não há como discordar dessa crítica, somente ressalvando que na primeira parte encontram-se capítulos fundadores da coleção, como os escritos por Boubou Hama e Ki-Zerbo, o de autoria de Jan Vansina e o de Hampaté-Bâ, de leitura indispensável. E, de fato, os capítulos da segunda parte, dedicados aos primórdios da história da humanidade na África, acabam por se tornarem difíceis de ler por seu detalhamento na explicação sobre os procedimentos da pesquisa arqueológica e a narrativa das descobertas no campo, as quais, na data de sua publicação (1982), já estariam desatualizadas. A busca, importante sem dúvida, pela afirmação da anterioridade africana na pré-história humana, se alicerça no trabalho arqueológico. Mas, numa obra como essa, um maior diálogo entre a arqueologia e a história, com maior foco nos grupos humanos, seria de fato desejável.

O volume 2, A África Antiga, organizado por G. Mokhtar, recebeu um verdadeiro bombardeio de críticas, quando de sua publicação. O mais forte argumento dos críticos foi o de o volume estar praticamente todo centrado na defesa do argumento do Antigo Egito ser negro. E, de fato, a importância dada ao tema é tamanha 
que, entre os vinte e nove capítulos, sete são sobre a história do Egito, nove sobre a região da Núbia (muitas vezes enfocando sua relação com o Egito) e quatro sobre o norte da África. O peso é evidente. Além dessa ênfase, o posicionamento metodológico dos capítulos desenvolvidos a partir das descobertas arqueológicas revela um tratamento sobre a história dos grupos humanos aparentemente mais centrado nas transformações da técnica do que nos modos de vida das pessoas. E, ao marcar em detalhe a passagem do neolítico para as fases de domínio da metalurgia na África, parece tirar o foco da cultura material como uma produção humana reveladora de uma história. Mas, novamente, há que se ressaltar muito especialmente nesse volume, em termos de conteúdo, linguagem e consistência historiográfica, os capítulos escritos por Ali Mahjoubi, Pierre Salama, J.E.G. Sutton, Abdul M. H. Sherif e John E. Parkington.

O volume 3, A África entre os séculos VII e XI, organizado por Mohammed El Fasi, tem como tema central o Islã e sua expansão sobretudo na África do norte. Esse tema orienta a periodização do tomo e está presente na maioria absoluta dos capítulos. As críticas que foram elaboradas se direcionaram não apenas à escolha de perspectiva, mas ao fato de o Islã ser tratado como um elemento da unidade pan-africana, sendo negligenciados os processos históricos ocorridos nas áreas não islamizadas. Sem dúvida, essa ausência é perceptível, ressaltando-se que a África Central aparece num só capítulo. No entanto, vale refletir sobre o fato de que em tantas outras obras de história o norte da África foi negligenciado ou simplesmente não reconhecido como parte do continente. Nesse volume da coleção, a região não apenas integra como de certa forma conduz uma parte considerável da história da África. E, finalmente, o penúltimo capítulo, de Abdoulaye Bathily com Claude Meillassoux, e o último capítulo, de autoria de Jean Devisse e Jan Vansina, fazem uma primorosa síntese dos cinco séculos abordados pelo terceiro volume, enfatizando as relações entre diferentes regiões do continente e as transformações relativas à produção de alimentos, relações com o meio ambiente e urbanização, entre outros aspectos. Em que pese o desenvolvimento da pesquisa histórica sobre África hoje, esses capítulos trazem uma abordagem com tal qualidade que resiste à passagem do tempo. Seu caráter de síntese faz desses textos instrumentos utilíssimos para o ensino de história da África em geral, e na preparação de aulas e projetos pedagógicos por professores da educação básica, em especial.

No volume 4, A África do século XII ao XVI, organizado por D.T. 
Niane, o foco regional privilegiado pelos autores é a África Ocidental, que ficou com um terço dos capítulos do livro. A África Centro-Ocidental novamente recebeu uma atenção reduzida, tendo sido tratada em apenas um capítulo, a refletir, talvez a pouca pesquisa sobre a região na época, inclusive Angola, que nos interessaria mais de perto. Não obstante, esse volume traz, além da Introdução, três grandes capítulos de síntese geral, ao final. $\mathrm{O}$ editor desse tomo, historiador dedicado não apenas à pesquisa como à transcrição de relatos da tradição oral, em seu capítulo sobre o Mali e a expansão manden, apresenta uma narrativa histórica referenciada em relatos de viajantes do mundo muçulmano e em imagens de objetos encontrados nas escavações arqueológicas da curva do Níger. No tocante ao escrito por D.T. Niane, vale dizer: nem mesmo as mudanças de perspectiva historiográfica e o avanço da pesquisa histórica tiram a atualidade desse capítulo, em sua abordagem e critério no uso de fontes de natureza tão distintas.

$\mathrm{O}$ volume 5 é aquele que maior interesse poderia despertar no público brasileiro, uma vez que seu tema central entrelaça-se com a história dos africanos na formação do nosso país: A África do século XVI ao XVIII, sob organização de Bethwell Allan Ogot. A crítica especializada internacional, ao recebê-lo, ressaltou o bom nível dos autores, mas criticou a perspectiva excessivamente carregada no destaque ao ponto de vista africano. Nesse sentido, um capítulo como o de Joseph Inikori sobre o tráfico de africanos escravizados, poderia ter considerado os debates já existentes na época da publicação. Hoje em dia, com as informações das bases de dados sobre o comércio transatlântico de cativos disponíveis online e o avanço das pesquisas regionais e locais nesse campo - com a singular contribuição de historiadores brasileiros - ${ }_{2}$ as análises neste volume sobre este tema e seus desdobramentos na diáspora africana estão em grande parte superadas. E mais: vincular essa atividade escravista a processos de constituição de países desenvolvidos e não desenvolvidos tampouco resiste a uma crítica mais atual. $\mathrm{Na}$ verdade, não se pode considerar que a visão de Inikori e a relativa pouca atenção que o volume dá ao tráfico atlântico sejam resultantes de uma perspectiva africana, em oposição a outra abordagem que prioriza os fatores externos ao continente. Nesse caso, o que se coloca em questão é a dimensão do protagonismo africano no negócio do tráfico, as estimativas quanto ao número de cativos envolvidos e a importância das relações entre a África, a Ásia e as Américas. Esses pontos remetem a uma perspectiva que pode não ser eurocêntrica. Ainda assim, a avaliação sobre a 
abordagem do comércio escravista não vale para todo o tomo, que, a propósito, é entre todos até aqui rapidamente analisados, aquele que traz o maior número de capítulos de síntese, com um destaque especial para o último, escrito pelo organizador do volume, B. A. Ogot.

O sexto volume, A África do século XIX á década de 1880, sob direção de Ade Ajayi, foi um dos mais positivamente comentados no momento de sua publicação. $\mathrm{O}$ editor, historiador nigeriano de origem iorubá, é considerado um dos mais importantes na tradicional escola de Ibadan de estudos históricos - grupo vinculado Journal of the Historical Society of Nigeria, revista publicada desde 1956 na Universidade de Ibadan. Nesse tomo, a abordagem proposta é a de caracterizar, a partir do estudo de diferentes processos em diversas partes do continente, "o século antes da colonização", para demonstrar que muitas transformações consideradas resultantes da ação colonial na verdade já estavam em curso antes da partilha da África. E nesse sentido, é bem sucedido, brindando o leitor com os resultados de sólidos trabalhos de pesquisa seguidos de boas análises nos diferentes capítulos. O volume conta com cinco capítulos de caráter geral, de síntese, e um deles é sobre a diáspora africana no mundo, escrito por J. E. Harris. Neste, em especial, há algumas informa- ções já superadas no tocante à diáspora no Brasil e seus efeitos, desde o percentual de entrada de cativos africanos no nosso território - $38 \%$ do total do tráfico transatlântico, ${ }^{3}$ sendo que as estimativas atuais apontam para cerca de $45 \%$-, até os episódios de rebeldia escrava, cuja menção não ultrapassou Palmares, e mesmo o silêncio quanto ao retorno de africanos libertos no Brasil para a Áfri$\mathrm{ca}$, onde foram fundar importantes colônias de "brasileiros" ou agudás. Tudo isso pode ser atribuído ao enorme desconhecimento sobre a história dos africanos no Brasil. Mas, no geral, o capítulo busca incluir aspectos diversificados e considerar as interações culturais na diáspora. Vale mencionar, ainda, como um dado indicador dos contatos acadêmicos e origem do organizador do volume, a divisão temática, com sete capítulos dedicados à África Ocidental e apenas um à África Centro-Ocidental.E justamente num tempo histórico em que tantas viagens foram realizadas, produzindo relatos, romances, matérias jornalísticas, e que tantos interesses e conflitos surgiram nessa área, sobretudo na bacia do rio Congo.

\footnotetext{
Percentagem dada por Curtin no seu livro clássico: The Atlantic Slave Trade: a Census, Madison: University of Wiscounsin Press, 1967. Ainda não existia o banco de dados de Eltis et alii, disponível em http://www.slavevoyages.org/ tast/index.faces, acessado em 05/04/ 2012.
} 
O volume 7 , editado por Adu Boahen, A África sob dominação colonial, 1880-1935, foi o que mais explicitamente se apresentou comprometido com uma visão a partir da África, e que incluiu capítulos de síntese sobre temas como a arte e a religião. Nesse tomo, seis capítulos foram desenvolvidos sobre a história das iniciativas e resistências africanas frente à conquista colonial, nas diferentes regiões. Esses capítulos deram um tom especial ao volume, e contribuem de uma forma especial para que se inverta a ordem de pensamento de professores e estudantes ao se debruçarem sobre o período abordado na história da África e do mundo. Explicar a chamada corrida colonial do século XIX pela história do capitalismo em expansão, esquecendo-se das relações de conflito, negociação e aliança produzidas nessa fase, significa perder o contexto histórico de vista. E isso é o que muitas vezes é feito, ainda que seja com a intenção de solidarizar-se com os "vencidos", levando a grandes equívocos de compreensão. Como disse a escritora nigeriana Chimamanda Adichie: "Comece uma história com as flechas dos nativos americanos, e não com a chegada dos britânicos, e você tem uma história totalmente diferente". ${ }^{4}$

Chimamanda Adichie, "Os perigos de uma única história", ${ }_{2}$ ttp://www.geledes.org.br/ em-debate/colunistas/4902-chimamandaadichie-o-perigo-de-uma-unica-historia
O oitavo e último volume, organizado por Ali Mazrui e Christopher Wondji, teve como título África desde 1935. Considerando o período analisado, e as delicadezas do trato com uma história que praticamente alcançava o tempo presente, além dos compromissos dos autores com autoridades de seus países - compromissos de ordem política, muitas vezes reforçados por uma participação em comum na luta pela independência era de se esperar que fosse um volume polêmico. Porém, as críticas centraram mais na abordagem dos temas: capítulos que abrangiam experiências coloniais distintas sem compará-las em seus aspectos mais relevantes, ou que pretenderam analisar uma situação colonial a partir da origem do governo colonizador, e não das características locais e do tipo de relação colonial estabelecida. E, sim, são perceptíveis esses equívocos. Afinal, as experiências coloniais se diferenciaram muito mais a partir de aspectos tais como a presença ou não de um contingente considerável de colonos europeus assentados, as atividades econômicas desenvolvidas, a presença ou não da cultura e religião islâmicas, entre tantos elementos. Nesse volume, a articulação entre influências externas e internas preten-

(texto); "http://www.ted.com/talks/ lang/pt/chimamanda_adichie_the danger_of_a_single_story.html (vídeo), acessados em 05/04/2012. 
dida pelo coordenador acabou por redundar num conjunto desigual, bastante variável em termos de consistência historiográfica. Alguns capítulos se apresentam como formulações e plataformas políticas - o que faz deles excelente material para análise, mas enfraquecem seu poder analítico. Por isso, deve-se ter cuidado ao utilizá-los como base para estudo. Enfim, o último volume da História Geral da África apresenta, como nenhum outro da coleção, uma análise de vários aspectos da vida social. Há capítulos dedicados à literatura, educação, línguas, artes, uma gama de temas fundamentais para a compreensão das sociedades africanas. $\mathrm{O}$ tratamento desses temas é por vezes muito geral, mas ainda assim iluminam aspectos da história africana até então pouco trabalhados na coleção.

Não faz muito tempo não havia no Brasil nenhum grande manual de História da África publicado. Quando uma síntese dessa natureza era necessária para uso nas aulas dessa disciplina - então pouco presente nas universidades brasileiras - recorriase à versões portuguesas, algumas em fotocópia, pela dificuldade em consegui-las. Hoje não apenas já foram publicadas no Brasil algumas obras de síntese da história africana, mas nos chegou essa coleção grandiosa. Sua importância é fundamental, em que pesem todas as críticas e reparos que possam ser feitos - necessários, porque faz parte do nosso ofício. Desenvolver uma análise crítica sobre capítulos e volumes da coleção História Geral da África é uma tarefa fundamental para estudiosos da história africana, e um exercício de aproximação a um trabalho historiográfico de características únicas. Além disso, é um privilégio tê-la ao alcance do olhar, na tela do computador, sem restrições de acesso.

Se para os interessados em geral, estudantes e professores de história da África nas universidades brasileiras, o uso da coleção História Geral da África é importante, muito mais ainda se torna para os professores da educação básica. Para o estudo e preparação das aulas para esses níveis de ensino, fundamental e médio, é fundamental ter um material bibliográfico que traga sínteses de aspectos e períodos e, ao mesmo tempo, exemplos variados de eventos e processos históricos que permitam tornar concreta a explicação formulada. O professor, para produzir o saber histórico em sala de aula, poderá fazer diferentes usos da coleção, desde que, como sempre e com qualquer obra de conteúdo específico, passe por seu olhar crítico. $\mathrm{O}$ fato de não ser uma obra recente não a desqualifica, pois como foi comentado, em muitos capítulos ainda é atual. E, quando não for, que se problematize. $\mathrm{O}$ fato de trazer uma história da África escrita em sua mai- 
or parte por autores africanos, numa obra de alcance internacional, também contribui para que se construa um olhar mais respeitoso sobre a produção de conhecimento no continente. Finalmente, a História Geral da
África, em oito expressivos volumes, nos arquivos de computadores e nas estantes de bibliotecas, torna-se uma confirmação concreta da frase inicial de Ki-Zerbo, e, portanto, um material de afirmação.

Mônica Lima

Universidade Federal do Rio de Janeiro 